\title{
A Study of the $\mathrm{O} / \mathrm{Ag}(111)$ system with scanning tunneling microscopy and x-ray photoelectron spectroscopy at ambient pressures
}

\author{
Christian Heine ${ }^{\mathrm{a}, *}$, Baran Eren ${ }^{\mathrm{a},{ }^{*}}$, Barbara A. J. Lechner ${ }^{\mathrm{a}}$, Miquel Salmeron ${ }^{\mathrm{a}, \mathrm{b}, * *}$ \\ ${ }^{a}$ Materials Sciences Division, Lawrence Berkeley National Laboratory, 1 Cyclotron Road, Berkeley, California 94720, United States \\ ${ }^{b}$ Department of Materials Science and Engineering, University of California, Berkeley, California 94720, United States \\ Elsevier use only: Received date here; revised date here; accepted date here
}

\begin{abstract}
The interaction of $\mathrm{O}_{2}$ with the $\mathrm{Ag}(111)$ surface was studied with scanning tunneling microscopy (STM) in the pressure range from $10^{-9}$ Torr to $1 \mathrm{~atm}$ at room temperature and with $X$-ray photoelectron spectroscopy (XPS) up to 0.3 Torr $\mathrm{O}_{2}$ in the temperature range from RT to $413 \mathrm{~K}$. STM images show that the $\mathrm{Ag}(111)$ surface topography is little affected in regions with large flat terraces, except for the appearance of mobile features due to oxygen atoms at pressures above 0.01 Torr. In regions where the step density is high the surface became rough under 0.01 Torr of $\mathrm{O}_{2}$, due to the local oxidation of Ag. Various chemical states of oxygen due to chemisorbed, oxide and subsurface species were identified by XPS as a function of pressure and temperature. The findings from the STM images and XPS measurements indicate that formation of an oxide phase, the thermodynamically stable form at room temperature under ambient $\mathrm{O}_{2}$ pressure, is kinetically hindered in the flat terrace areas but proceeds readily in regions with high step density.
\end{abstract}

Keywords: Ag(111), oxidation, APSTM, APXPS, ambient pressure, surface science

* These authors contributed equally to this work.

**Corresponding author Tel: +1-510-486-6704 E-mail address:mbsalmeron@lbl.gov 


\section{Introduction}

Silver-based catalysts are used in industry for selective methanol oxidation to formaldehyde, and for ethylene epoxidation reactions [1], carried out typically at 420-550 K (epoxidation) and at $950 \mathrm{~K}$ (methanol oxidation). These reactions were studied with surface science techniques in the past decades [1-3]. For ethylene epoxidation, both the $\operatorname{Ag}(110)$ and $\operatorname{Ag}(111)$ surfaces were found to exhibit a similar selectivity [4] . During methanol oxidation on the other hand, the most active surface was found to be faceted with preferred (111) orientation [5], which makes this surface more relevant for surface science studies.

To understand the atomic-scale processes occurring during these reactions in more detail, the Ag/oxygen system was investigated intensively, predominantly with X-ray photoelectron spectroscopy (XPS) [6-19] and scanning tunneling microscopy (STM) [14-16,20-22]. It was found that the oxidation behavior of the catalytically relevant $\operatorname{Ag}(110)$ and $\operatorname{Ag}(111)$ surfaces is quite different. Although atomic (chemisorbed) oxygen on $\operatorname{Ag}(110)$ can be formed by dissociative adsorption of $\mathrm{O}_{2}$ under ultra-high vacuum (UHV) conditions [19], its formation on $\mathrm{Ag}(111)$ requires exposure to at least $10^{-3}$ Torr of $\mathrm{O}_{2}[6-10]$. Only aggressive oxidation agents like $\mathrm{NO}_{2}$ [23,24] or atomic oxygen $[15,25,26]$ can oxidize the $\operatorname{Ag}(111)$ surface under UHV conditions. However, the oxidation of $\operatorname{Ag}(111)$ with $\mathrm{O}_{2}$ is more relevant since $\mathrm{O}_{2}$ is the oxidizing agent used under industrial conditions. Therefore, the oxidation of a $\operatorname{Ag}(111)$ surface by $\mathrm{O}_{2}$ is best explored by in situ techniques such as ambient pressure (AP) XPS [27,28] and STM [29]. To date, APXPS and APSTM studies of the interaction of $\mathrm{Ag}(111)$ with $\mathrm{O}_{2}$ (including studies in an ethylene epoxidation feed) were only performed at temperatures $\geq 375 \mathrm{~K}[11,13,16,30,31]$ because the temperature range is most relevant for the above mentioned catalytic reactions. However, under these conditions multiple oxygen species are present making their assignment problematic. Investigations at room temperature $(\mathrm{RT} \approx 298 \mathrm{~K}$ ) (with subsequent heating to reaction temperatures) are needed to identify the initial state of the $\operatorname{Ag}(111) / \mathrm{O}_{2}$ system and to follow the evolution of oxygen species.

Furthermore recent studies of catalysts containing small amounts of Ag alloyed with Au in a nanoporous matrix revealed good catalytic performance for oxidative methanol coupling at temperatures as low as 300 to $375 \mathrm{~K}$ [32]. A detailed investigation of the oxidation of $\operatorname{Ag}(111)$ at room temperature is thus relevant for a fundamental understanding of the process as well as for the optimization of catalyst materials. 
In the present work, we were able to identify various oxygen species and the oxidation state of $\operatorname{Ag}(111)$ by combining core and valence level APXPS and APSTM. We show that the morphology of the $\operatorname{Ag}(111)$ surface does not change significantly in an oxygen atmosphere at room temperature (RT). Instead, STM images show that terraces remain flat and separated by monatomic steps, as in UHV. APSTM measurements under pure oxygen gas reveal that large atomically flat terraces contain only disordered atomic oxygen at $\mathrm{O}_{2}$ pressures of up to 90 Torr. Oxidation and roughening of the surface was observed, however, in regions of the surface containing a high density of steps. While oxide formation is energetically favorable under ambient temperature and pressure conditions, our results indicate that this process is kinetically hindered.

\section{Experimental}

A $\operatorname{Ag}(111)$ sample (Surface Preparation Laboratory, The Netherlands) was cleaned by repeated cycles of $\mathrm{Ar}^{+}$ sputtering (15-30 min, $1 \mathrm{keV})$ and annealing at $773 \mathrm{~K}(10 \mathrm{~min})$. The crystal was found to exhibit areas comprising wide terraces of (111) orientation, as well as an area with a high step density, due to some local mechanical deformation. This circumstance allowed us to compare the oxidation behavior of flat vs highly stepped regions. While STM measurements typically cover regions less than $1 \mu \mathrm{m}$ across, so that the flat and highly stepped regions can be imaged separately, the same is not true for the XPS measurements, due to the larger spot size (about $200 \times 60 \mu \mathrm{m}^{2}$ ) of the X-ray beam. The $\mathrm{O}_{2}$ gas was introduced into the APSTM and APXPS chambers through leak valves, starting from base pressures in the low $10^{-10}$ Torr range. The pressure was measured with MKS 722A Baratron capacitance and Granville Phillips 275 Convectron Pirani pressure gauges.

APSTM measurements were performed at RT in a home-built microscope. All images were recorded in constant current mode using Pt/Ir tips and applying the bias to the sample. Scanning parameters are indicated in the figure captions.

APXPS experiments were performed at the beam line 11.0.2 endstation of the Advanced Light Source in Berkeley. To achieve a clean environment, a nitrogen plasma was ignited prior to conventional bake-out. Survey spectra were acquired at a photon energy $\left(\mathrm{E}_{\mathrm{ph}}\right)$ of $735 \mathrm{eV}$ to check for contamination before collecting high resolution spectra. The spectra showed no significant contributions from species other than those related to the $\mathrm{Ag}$ and $\mathrm{O}$ photoelectrons and Auger-Meitner lines, as shown in representative examples in Fig. 1. The C1s spectra in the inset are normalized to the 
O1s spectra (see Fig. 6a) after background correction. Thus, the concentration of contaminants on the surface can be estimated to be below 1 atomic percent. Photon energies of $575 \mathrm{eV}$ for $\mathrm{Ag} 3 \mathrm{~d}, 735 \mathrm{eV}$ for O 1s, and $490 \mathrm{eV}$ for C 1s were used to produce photoelectrons with kinetic energies $\left(\mathrm{E}_{\mathrm{kin}}\right)$ around $200 \mathrm{eV}$ for core level spectra, resulting in an inelastic mean free path (IMFP) of approximately $0.5 \mathrm{~nm}$ (estimated for $\mathrm{Ag}$ ) [33]. The peak position energies are always referred to the Fermi level $\left(\mathrm{E}_{\mathrm{f}}\right)$ measured in the same spectrum. The $\mathrm{O}$ 1s spectra were fitted with GaussianLorentzian functions using a linear background. For the $\mathrm{Ag} 3 \mathrm{~d}$ spectra a Doniach-Sunjic function convoluted with a Gaussian-Lorentzian function was used after a quadratic background subtraction. Valence level spectra were acquired at $\mathrm{E}_{\mathrm{ph}}$ of $270 \mathrm{eV}$. Because the pressure in beam line 11.0.2 is limited to the Torr regime, we acquired spectra at 0.3 Torr of $\mathrm{O}_{2}$ at temperatures between $298 \mathrm{~K}$ and $413 \mathrm{~K}$.

\section{Results and Discussion}

\subsection{The Ag(111) surface in UHV and in air}

The surface morphology of the $\operatorname{Ag}(111)$ surface was first investigated by STM in UHV and in air. In UHV, the images (not shown here) show steps with frizzled step edges separating terraces, the frizzling being due to the fast diffusion of step-edge Ag atoms at RT [14]. After exposure to air for two hours, the surface displayed similar large terraces and step structures as in UHV, as in the example of Fig. 2a. As mentioned above, the crystal used in this study contained a defective (deformed) region where high step densities could be found, as shown in the image in Fig. 2b, with steps roughly parallel to each other and separated by distances of about $1 \mathrm{~nm}$. After exposure to air this stepped surface became rough (Fig. 2c).

The observation of large, atomically flat terraces on $\mathrm{Ag}(111)$ in air (even after 2 hours) stands in contrast to many other metal surfaces of (111) orientation, where oxidation rapidly roughens the surface. This is likely due to kinetic limitations, since $\mathrm{Ag}_{2} \mathrm{O}$ is energetically more stable [34,35]. Our interpretation is supported by the observed roughening in the highly stepped region shown in Fig. 2c.

\subsection{Pressure dependent STM}

To further investigate the $\mathrm{O}-\mathrm{Ag}(111)$ interaction we examined the surface structure with APSTM over the pressure range from UHV to atmospheric oxygen pressures. These studies were complemented with APXPS core level and 
valence band studies at 0.3 Torr $\mathrm{O}_{2}$ in a temperature range from $298 \mathrm{~K}$ to $413 \mathrm{~K}$ to correlate oxygen species with modifications in the Ag electronic structure and with the topography observed in the STM images.

\subsubsection{Effect of oxygen on the flat regions}

Fig. 3 shows the evolution of the $\mathrm{Ag}(111)$ surface at $\mathrm{RT}$ as a function of $\mathrm{O}_{2}$ pressure. At 0.01 Torr of $\mathrm{O}_{2}$ (Fig. 3a and the magnified area in Fig. 3b), many dark spots on the terraces are apparent, which is the typical STM contrast of atomic oxygen on most metal surfaces. A line profile over the spots shows a depth of roughly $35 \mathrm{pm}$, with a full width at half maximum (FWHM) of roughly $1 \mathrm{~nm}$ (Fig. 3k). Similar features have been observed in UHV-STM studies (at $4 \mathrm{~K}$ ) of $\mathrm{Ag}(111)$ exposed to $\mathrm{NO}_{2}$ at $470 \mathrm{~K}$ [20]. Using Monte Carlo simulations together with STM imaging, Carlisle et al. [20] assigned the depressions to subsurface oxygen atoms at octahedral interstitial sites in the second layer. In contrast, density functional theory (DFT) calculations by other authors indicate that the depressions are due to atomic oxygen atoms at fcc sites on $\operatorname{Ag}(111)$, which is the most stable adsorption site at low coverage [36-38]. We similarly adopt this assignment in the present paper. Larger dark spots are also visible, although less frequently, which we interpret as due to an accumulation of oxygen atoms.

Fig. $3 \mathrm{c}$ was acquired at the same location as Fig. 3a, but in the presence of 0.3 Torr of $\mathrm{O}_{2}$. The surface now shows a waviness not present before, seen better in the magnified image of Fig. 3d. In order to enhance the contrast, derivative images at these two pressures are shown in Figs. $3 \mathrm{i}$ and j, respectively. We attribute the corrugation contrast to oxygen accumulation in the subsurface. DFT calculations have indeed predicted atomic oxygen to diffuse and occupy the octahedral sites one layer below the surface for coverages above 0.25 monolayers (ML) [34,39].

Figs. 3e and $f$ show the $\mathrm{Ag}(111)$ surface in the presence of 90 Torr of $\mathrm{O}_{2}$. These images, as well as others acquired at 10 Torr, are very similar to the images acquired in air. Remarkably, there is no apparent corrugation in tunneling contrast at this pressure, other than that arising from atomic oxygen on the surface (Fig. 3f). We attribute the lack of corrugation to saturation of the subsurface sites with atomic oxygen. These results indicate that neither a bulk $\operatorname{Ag}_{2} \mathrm{O}$ phase nor a surface $\mathrm{Ag}(111)-\mathrm{p}(4 \times 4)-\mathrm{O}$ reconstruction is formed in the presence of atmospheric $\mathrm{O}_{2}$ in the scale of hours. Although theoretical calculations predict the oxide to be stable at RT at these pressures [35], our results show that kinetic limitations prevent growth of the oxide phase.

Once $\mathrm{O}_{2}$ in the gas phase was pumped away the surface looks once again corrugated, which we interpret as due to the subsurface oxygen gradually diffusing out and desorbing (Figs. $3 g$ and h). Fig. 31 shows a line profile taken from Fig. $3 \mathrm{~h}$ at the position indicated by arrows. It shows the overall tunneling corrugation to be around $40 \mathrm{pm}$ (peak to 
peak), together with many 5-20 pm depressions due to dark spots from atomic oxygen on the surface. The spots are separated on average $0.8-0.9 \mathrm{~nm}$ from each other, likely due to repulsion between oxygen atoms [20].

Fig. 4 shows time-lapsed APSTM images at 10 Torr of $\mathrm{O}_{2}$, with a red dashed line as a reference to compare identical positions. From one image to the next, the position of the dark spots changes, indicating again that atomic oxygen is mobile on the time scale of several seconds.

\subsubsection{Effect of oxygen on the stepped regions}

To study the effect of steps on the oxidation of a $\operatorname{Ag}(111)$ surface, we investigated the high step density region mentioned before. In the presence of $2 \times 10^{-8}$ Torr of $\mathrm{O}_{2}$ (Fig. 5a), the surface appears similar to that in UHV (Fig. 2b). However, when the $\mathrm{O}_{2}$ pressure was increased to 0.01 Torr, the terrace width increased in size and the surface started to break up into clusters (Fig. 5b). A further increase in average step width and cluster size was observed at higher oxygen pressures of 0.3 Torr (Fig. 5c) and 90 Torr (Fig. 5d). We attribute the formation of clusters to the oxidation of Ag. These results indicate that the kinetic barriers that prevent rapid oxidation on the large (111) terraces are not present in the stepped regions which feature large numbers of under-coordinated $\mathrm{Ag}$ sites. 


\section{$3.3 \mathrm{XPS}$ at a near-ambient $\mathrm{O}_{2}$ pressure}

\subsubsection{Core level O 1s spectra}

Figs. $6 \mathrm{a}$ and $\mathrm{b}$ show the $\mathrm{O} 1 \mathrm{~s}$ and $\mathrm{Ag} 3 \mathrm{~d}$ regions of the APXP spectra. Prior to exposure to 0.3 Torr of $\mathrm{O}_{2}$, no peaks were observed in the $\mathrm{O} 1 \mathrm{~s}$ region (Fig. 6a-i). In the presence of 0.3 Torr of $\mathrm{O}_{2}$ at $\mathrm{RT}$, three different oxygen species can be identified (Fig. 6a-ii), with the $\mathrm{O} 1$ s peak positions at binding energies (BE) of $531.5 \pm 0.1 \mathrm{eV}, 530.2 \pm 0.1 \mathrm{eV}$ and $528.9 \pm 0.1 \mathrm{eV}$, respectively. As the surface temperature was increased to $373 \mathrm{~K}$, the component at $531.5 \mathrm{eV}$ disappeared (Fig. 6a-iii). After increasing the temperature to $423 \mathrm{~K}$, a new oxygen component at $528.1 \pm 0.1 \mathrm{eV}$ appeared (Fig. 6a-iv), while the intensity of the component at $530.2 \mathrm{eV}$ was reduced significantly. Once the sample was cooled back down to RT and the measurement chamber evacuated to $5 \times 10^{-9} \mathrm{Torr}$, all four components could be observed simultaneously (Fig. 6a-v).

To compare the intensities of different oxygen species at different conditions, the intensity ratio of each oxygen component to $\mathrm{Ag} 3 \mathrm{~d}_{5 / 2}$ is shown in Table 1 after photo-ionization cross section [40] and asymmetry parameter corrections [40]. Several trends are prominent: The $531.5 \mathrm{eV}$ component is a minor feature in all the conditions studied. The peak located at $530.2 \mathrm{eV}$ decreases with increasing temperature, i.e., at $373 \mathrm{~K}$ its normalized intensity is half of that at $298 \mathrm{~K}$, and at $413 \mathrm{~K}$ it is only a minor feature. The intensity of the feature at $528.9 \mathrm{eV}$ is present in appreciable amounts under all conditions and it is mostly unaffected by the evacuation of the chamber. The peak at $528.1 \mathrm{eV}$ is the major species at $413 \mathrm{~K}$. After cooling to $298 \mathrm{~K}$ in the presence of $0.3 \mathrm{Torr}$ of $\mathrm{O}_{2}$ and then evacuating the chamber, about half of the intensity of this component remains.

These $\mathrm{O} 1 \mathrm{~s}$ peaks have been reported in the literature and assigned to various component species. Below, we discuss each peak in turn and propose specific species.

$\underline{531.5 \mathrm{eV}}$ : We assign this peak, which occurs only at RT, to minority $\mathrm{OH}$-groups resulting from residual water in the measurement chamber, detected by mass spectroscopy. Such OH-groups have been reported to produce a feature at around $531.7 \mathrm{eV}[41,42]$, in agreement with our measurements.

$\underline{530.2 \mathrm{eV}}$ : Features between 530.0 and $530.5 \mathrm{eV}$ were previously assigned to various species [6-17], and their nature is still disputed. This peak was previously obtained after long exposure to $\mathrm{O}_{2}$ at a pressure of $10^{-3}$ Torr [610], or after exposure to aggressive oxidizers such as $\mathrm{NO}_{2}$ under UHV conditions [12,14-16]. Joyner et al. [9] and Grant et al. [10] assigned it to atomic oxygen located in the subsurface. It was further stated that the exact peak 
position depends on the amount of oxygen pre-dissolved in the bulk [6]. In contrast, Bukhtiyarov et al. assigned this species to chemisorbed oxygen on the surface [7]. King et al. [20] and Reicho [12] related this type of oxygen to a disordered chemisorbed structure using STM and surface x-ray diffraction in combination with XPS. Finally, Wintterlin and coworkers observed two species at $530.7 \mathrm{eV}$ and at $530.2 \mathrm{eV}$ [14]. Their corresponding STM images showed either a disordered phase or a $(7 \mathrm{x} \sqrt{ } 3)$ rect structure consisting of stripes along the [11-2] direction. A further study from this group assigned the $530.7 \mathrm{eV}$ component to subsurface oxygen and the $530.2 \mathrm{eV}$ component to surface oxygen [15]. It is also critical to mention here that carbonates can equally produce peaks with energies between 530 and $531 \mathrm{eV}$ [43]. Since our survey spectra (Fig. 1) revealed no significant carbon contamination under any condition, however, a carbonate contribution to the $\mathrm{O} 1 \mathrm{~s}$ spectra can be excluded in the present case. The $530.2 \mathrm{eV} \mathrm{O} 1 \mathrm{~s}$ species is the main component in $0.3 \mathrm{Torr}_{2}$ at $\mathrm{RT}$. According to the finding from our APSTM investigations under the same conditions, we attribute this species to atomic oxygen at the surface and in near-surface regions.

528.9 eV: This peak, reported previously by Schlögl and coworkers $[6,8,44]$, has the same BE as bulk $\mathrm{Ag}_{2} \mathrm{O}$. They assigned this peak to a two-dimensional oxygen species also found under methanol oxidation reaction conditions [8]. In the present study, unlike other peaks, this feature was barely influenced by temperature variations or by the evacuation of $\mathrm{O}_{2}$ (see Table 1), in agreement with the previous reports. The finding in the APSTM part reveals that oxide-like structures are formed at step edges. Furthermore, Li et al. [35] reported DFT calculation that showed atomic oxygen in under-coordinated sites (for instance step edges) is stable up to $830 \mathrm{~K}$ in a wide pressure range covering 0.3 Torr. This is in agreement with our findings. According to the similarity in peak position of the $528.9 \mathrm{eV}$ component with the $\mathrm{Ag}_{2} \mathrm{O}$, we assign this species to be $\mathrm{Ag}$ oxide formed at step edges of the $\operatorname{Ag}(111)$ surface.

528.1 eV: This peak was assigned in the literature to $\mathrm{O}$ in the $\mathrm{Ag}(111)-\mathrm{p}(4 \times 4)-\mathrm{O}$ reconstruction. The same peak was observed when the surface was prepared using $\mathrm{O}_{2}$ at temperatures around $413 \mathrm{~K}[3,7,45]$, and at slightly higher $\mathrm{BE}, 528.3 \mathrm{eV}$ in ref. [16] and $528.2 \mathrm{eV}$ in ref. [12] when $\mathrm{NO}_{2}$ was used as oxidizing agent. However, other (coexisting) O-surface reconstructions can also lead to peaks between 528.1 and $528.3 \mathrm{eV}$ on the $\mathrm{Ag}(111)$ surface [3]. Furthermore, similar peaks were also found on the $\mathrm{Ag}(110)$ surface and assigned to ordered O-surface phases [19]. The appearance of this oxygen feature in the O $1 \mathrm{~s}$ spectrum is concurrent with a feature at a binding energy $0.5 \mathrm{eV}$ below the metallic component of $\mathrm{Ag} 3 \mathrm{~d}_{5 / 2}$ which was also assigned to the $\mathrm{Ag}(111)-\mathrm{p}(4 \times 4)-\mathrm{O}$ surface 
reconstruction [7,22]. When the $528.1 \mathrm{eV}$ appeared in our experiments the corresponding feature in the $\mathrm{Ag} 3 \mathrm{~d}$ spectrum was also present (Fig. 6b), as discussed below.

We attribute the $528.1 \mathrm{eV}$ peak in the $\mathrm{O} 1 \mathrm{~s}$ spectrum and the corresponding feature in the $\mathrm{Ag} 3 \mathrm{~d}$ spectrum to ordered O-surface structures. These XPS-features are not unique features for a specific oxygen surface reconstruction but were always found when an oxygen reconstruction was observed.

\subsubsection{Core level Ag 3d spectra}

The Ag 3d core level spectra are shown in Fig. 6b. According to Andersen et al., a surface core level shift cannot be observed in the $\mathrm{Ag} 3 \mathrm{~d}$ spectrum of $\mathrm{Ag}(111)$ [46]. Accordingly, we fitted the $\mathrm{Ag} 3 \mathrm{~d}_{5 / 2}$ and $\mathrm{Ag} 3 \mathrm{~d}_{3 / 2}$ peaks as a single doublet in the UHV spectra (Fig. 6b-i). However, small deviations between the fit and the experimental data at the high BE side of both peaks can be observed, as reported previously by Barrie and Christensen [47]. The physical origin of this small deviation is the excitation of plasmons [48]. The plasmon features $3.7 \mathrm{eV}$ above the Ag 3d line were fitted with a convolution of a Gaussian and a Lorentzian function. The center of the fit of our $\mathrm{Ag} 3 \mathrm{~d}_{5 / 2}$ peak is at $368.15 \mathrm{eV}$ for metallic silver, the same as previously reported for the $\operatorname{Ag}(111)$ [7] $\operatorname{and} \operatorname{Ag}(110)$ surfaces [13]. In the presence of 0.3 Torr of $\mathrm{O}_{2}$ at $298 \mathrm{~K}$ (Fig. 6b-ii) and $373 \mathrm{~K}$ (Fig. 6b-iii), the line shape of the $\mathrm{Ag} 3 \mathrm{~d}_{5 / 2}$ peak remains the same as in UHV. After increasing the temperature to $413 \mathrm{~K}$, however, a second, broader component appears at $0.5 \mathrm{eV}$ lower BE (Fig. 6b-iv). Spectrum Fig. 6b-v was acquired at the same conditions as Fig. $6 \mathrm{~b}$-iv but with $\mathrm{E}_{\mathrm{kin}}=550 \mathrm{eV}$, corresponding to an IMFP of approximately $1 \mathrm{~nm}$ [33]. As the surface sensitivity decreases with this increase in probe depth, the new component at lower BE clearly has a smaller intensity with respect to the metallic $\mathrm{Ag}$ component, suggesting that it is due to a surface species in agreement with our assignments for the $528.1 \mathrm{eV} \mathrm{O1s-peak.} \mathrm{After} \mathrm{cooling} \mathrm{the} \mathrm{sample} \mathrm{back} \mathrm{to} \mathrm{RT} \mathrm{in} 0.3$ Torr $\mathrm{O}_{2}$ and subsequently evacuating the chamber this component can still be observed, albeit with reduced intensity (Fig. 6b-vi).

The Ag 3d core level is fairly insensitive to the oxidation of Ag [49]. The Ag 4d density of states (DOS) is not significantly broadened by the interaction of Ag with oxygen which can be seen in Fig. 7. Therefore, the center

of the Ag 4d DOS is almost unchanged with respect to the Fermi level. The center of the Ag 4d DOS is a measure of the electrostatic potential acting on the $\mathrm{Ag} 3 \mathrm{~d}$ core level. Simply speaking, the $\mathrm{Ag} 3 \mathrm{~d}$ core level is shielded by 
the hardly affected Ag 4d DOS. However, when the $528.1 \mathrm{eV}$ peak appears, an additional peak at $367.6 \mathrm{eV}$ (low binding energy side of the metallic $\mathrm{Ag}$ line) in the $\mathrm{Ag} 3 \mathrm{~d}$ core level can be observed. A shift of the $\mathrm{Ag} 3 \mathrm{~d}$ peak to a lower BE is counter-intuitive in the context of the electrostatic potential model [50,51]. Since the Ag 4d DOS is also hardly affected in the presence of the $367.6 \mathrm{eV}$ peak (see Fig. 7a and b-v), a change of the electrostatic potential cannot be the reason for the negative core level shift. In contrast, the Ag 5s DOS is clearly affected by oxygen $2 \mathrm{p}$ states as seen in Fig 7a and b-v (see details in section 3.3.3). An electron transfer from the Ag 5s states to the oxygen $2 \mathrm{p}$ states takes place. The screening situation ( $\mathrm{Ag} \mathrm{d}^{10} \mathrm{~s}^{2}$ [49]) of the $\mathrm{Ag} 3 \mathrm{~d}$ core hole created in the photoexcitation process is now changed because the $\mathrm{Ag} 5 \mathrm{~s}$ electron is transferred to oxygen. The extra (screening) electron occupies a bonding instead of an anti-bonding state [49]. It is well known, that core level shifts are caused by the difference of the initial (in this case clean $\mathrm{Ag}$ and oxidized Ag) and final states (different screening situations). Changes in the electrostatic potential are related to differences of the initial states [50,51]. As mentioned above, the Ag 4d DOS and therefore the electrostatic potential are hardly affected by the interaction of Ag with oxygen. Thus the negative shift of the $\mathrm{Ag} 3 \mathrm{~d}$ core level is attributed to different screening situations and therefore final states effects [49]. Furthermore the shift to lower BE indicates that this kind of oxygen species has a more 'ionic' character than the other observed species (charge transfer for Ag 5 s to oxygen $2 p$ takes place), in agreement with previous studies, where this type of oxygen was termed 'nucleophilic' [1,52]. It should be mentioned that initial state effects can also cause negative core level shifts upon rehybridization as seen in alloys [53].

\subsubsection{Valence band}

Valence band spectra were also acquired to consolidate the peak assignments in the core level by probing the change in DOS. Fig. 7a shows the XPS valence band spectra taken at different conditions after normalization to the maximum state at around $4.4 \mathrm{eV}$. Fig. $7 \mathrm{a}-\mathrm{i}$ shows the gas phase spectrum of 0.3 Torr $\mathrm{O}_{2}$. It has features at around $20 \mathrm{eV}, 16 \mathrm{eV}, 13.8 \mathrm{eV}$ and $12 \mathrm{eV}$ below $\mathrm{E}_{\mathrm{f}}$. The same gas phase features are also observed in spectra Fig. 7iii-v, however the peak positions are shifted to lower BE due to introduction of the sample that modifies the vacuum potential according to the work function of $\mathrm{Ag}(111)$ [54,55]. The gas phase feature at a $\mathrm{BE}$ of $8 \mathrm{eV}$ will be discussed in more detail below because it overlaps with the $\mathrm{Ag} 4 \mathrm{~d}$ states. 
The spectrum in Fig. 7a-ii shows the valence band of $\mathrm{Ag}(111)$ in UHV. The intense features between $3.8 \mathrm{eV}$ and $8.0 \mathrm{eV}$ are mainly related to the $\mathrm{Ag} 4 \mathrm{~d}$ states. The flat region between $\mathrm{E}_{\mathrm{f}}$ and $3.8 \mathrm{eV}$ originates mainly from $\mathrm{Ag} 5 \mathrm{~s}$ emissions $[34,35,49]$. Most of the changes in the presence of $\mathrm{O}_{2}$ appear between $\mathrm{E}_{\mathrm{f}}$ and $10 \mathrm{eV}$. We therefore present difference spectra in this energy range in Fig. 7b, obtained by subtracting the UHV reference (ii) from spectra (iii-vi). In the presence of 0.3 Torr of $\mathrm{O}_{2}$ at RT, the difference spectrum (Fig. 7b-iii) reveals four main features: A peak at $4.2 \mathrm{eV}$ with a shoulder at $3.6 \mathrm{eV}$ and a smaller shoulder at $2.2 \mathrm{eV}$, a dip at $5.0 \mathrm{eV}$, and two broader peaks at 5.2-6.0 eV and 6.0-8.0 eV, respectively. Other than the peak at $2.2 \mathrm{eV}$, all features decrease in amplitude as the temperature is increased to $373 \mathrm{~K}$ (Fig. 7b-iv). The situation changes notably at $413 \mathrm{~K}$ (Fig. 7bv): The peak at $2.2 \mathrm{eV}$ broadens, the peak at $4.2 \mathrm{eV}$ broadens and becomes more intense than at RT, the shoulder at $3.6 \mathrm{eV}$ disappears, and the amplitude of the dip at $5.0 \mathrm{eV}$ increases compared to that at $373 \mathrm{~K}$. The two features between $5.2 \mathrm{eV}$ and $8.0 \mathrm{eV}$ are also modified, resulting in a peak at $5.4 \mathrm{eV}$ with two shoulders at $6.8 \mathrm{eV}$ and 7.4 $\mathrm{eV}$. Once the surface is cooled down to $298 \mathrm{~K}$ and the measurement chamber is evacuated to remove the $\mathrm{O}_{2}$ atmosphere, the difference spectrum looks like a superposition of the difference spectra in Figs. 7b-iii and 7b-v (Fig. 7b-vi).

Features related to disordered atomic oxygen: The valley at $5.0 \mathrm{eV}$ (seen in all difference spectra in Fig. 7b) was also previously observed in several ultraviolet photoelectron spectroscopy (UPS) studies [7,31,56,57]. This feature has been attributed to shifts or decrease in the Ag 4d DOS due to the interaction with oxygen $[34,35,49]$. The attenuation of the aforementioned features at $373 \mathrm{~K}$ with respect to $298 \mathrm{~K}$ occurs simultaneously with a decrease in intensity of the $530.2 \mathrm{eV}$ core level $\mathrm{O} 1 \mathrm{~s}$ peak which originates from atomic (chemisorbed) oxygen on the surface and in the subsurface (compare with Fig. 6a and Table 1). The broad peak between $6.0 \mathrm{eV}$ and 8.0 $\mathrm{eV}$ overlaps with a gas phase peak (Fig. 7a-i), so parts of the changes in this region are caused by the gas phase. DFT calculations suggested that the high BE end of the $\mathrm{Ag} 4 \mathrm{~d}$ states overlaps with $\mathrm{O} 2 \mathrm{p}$ states when the $\mathrm{Ag}(111)$ surface is covered with oxygen [34,35,49]. We thus assign the features between $5.2 \mathrm{eV}$ and $8.0 \mathrm{eV}$ to $\mathrm{O} 2 \mathrm{p}$ states. The appearance of the peak at $4.2 \mathrm{eV}$ and the shoulder at $3.6 \mathrm{eV}$ can both result from $\mathrm{O} 2 \mathrm{p}$ states or shifted $\mathrm{Ag} 4 \mathrm{~d}$ states.

Features related to Ag oxide at step edges: In general, oxidation leads to a broadening of the d-states, but this is not very pronounced for $\mathrm{Ag}$ [49]. The shoulder at $2.2 \mathrm{eV}$ can be seen at $298 \mathrm{~K}$ and $373 \mathrm{~K}$ with a similar amplitude. From Table 1, it can be seen that the atomic concentration of the $528.9 \mathrm{eV}$ component does not change 
significantly as a function of temperature. We therefore relate this valence band feature to the $528.9 \mathrm{eV}$ peak and to $\mathrm{Ag}$ oxide at step edges. DFT calculations revealed a similar feature, which was assigned to O $2 \mathrm{p}$ states of a silver oxide phase in the region between $\mathrm{E}_{\mathrm{f}}$ and the lower energy end of $\mathrm{Ag} 4 \mathrm{~d}$ states $[34,35,49]$

Features related to ordered O-surface structures on $\mathrm{Ag}(111)$ : Due to the fact that the $528.1 \mathrm{eV}$ peak is the main feature in the $\mathrm{O} 1 \mathrm{~s}$ spectrum at $413 \mathrm{~K}$, we assign the distinct valence band features at this temperature to the $\mathrm{O} 2 \mathrm{p}$ states of ordered O-surface structures on $\mathrm{Ag}(111)$. It should also be noted that the region between $\mathrm{E}_{\mathrm{f}}$ and the $\mathrm{Ag}$ $4 \mathrm{~d}$ onset has some similarity to the valence band structure of $\mathrm{Ag}_{2} \mathrm{O}$ [44], evident as a peak at $2.2 \mathrm{eV}$, albeit broader than at lower temperatures. After evacuating the chamber, valence band features characteristic of ordered Osurface structures on $\operatorname{Ag}(111)$ remain, in line with the $528.1 \mathrm{eV}$ component supporting our assignments.

\section{Conclusion}

Our combined APSTM/APXPS study gives new insights into the oxidation behavior of the $\mathrm{Ag}(111)$ surface. The STM images of flat terrace regions show no indication of oxide formation up to atmospheric pressures (air) at RT, with the terraces remaining atomically flat. Mobile features with dark contrast are observed at a pressure of 0.01 Torr $\mathrm{O}_{2}$. They are assigned to atomic chemisorbed oxygen on the $\mathrm{Ag}(111)$ surface. The density of spots increases with pressure up to 0.3 Torr, indicating an increase in oxygen coverage. Additionally an underlying waviness of the tunneling contrast was observed in the STM images which disappears at 10 to 90 Torr and returns again after evacuating the APSTM chamber. The waviness is associated with oxygen atoms diffused to subsurface sites, which become saturated at higher pressures, a situation that is reversed by returning to low pressure. This type of oxygen is at the origin of the main peak at $530.2 \mathrm{eV}$ of the XPS O $1 \mathrm{~s}$ spectrum in 0.3 Torr $\mathrm{O}_{2}$ at RT. Valence band features appear at the onset (4.2 eV with shoulder at $3.6 \mathrm{eV}$ ) and end (5.2-8 eV) of the $\mathrm{Ag} 4 \mathrm{~d}$ states. An increase in temperature leads to desorption of atomic chemisorbed oxygen $(373 \mathrm{~K})$.

Although it has been predicted that, for instance, the ordered $\operatorname{Ag}(111)-\mathrm{p}(4 \times 4)-\mathrm{O}$ phase is stable at $\geq 0.3$ Torr at RT [35] we did not observe any ordered O-surface phase in our STM images, nor their signatures in the XPS O 1s/Ag 3d spectra without temperature treatment of the $\operatorname{Ag}(111)$ sample. This leads us to conclude that this phase must be metastable. Thus an energy barrier (activation energy) has to be overcome to form the thermodynamically stable phases. 
After exposing the $\mathrm{Ag}(111)$ surface to $\geq 0.01$ Torr $\mathrm{O}_{2}$, STM images revealed cluster formation in regions with a high step density, suggestive of $\mathrm{Ag}$ oxide formation. Since the $528.9 \mathrm{eV}$ component in the O 1s spectrum has a similar binding energy to that in $\mathrm{Ag}_{2} \mathrm{O}$ we can attribute the clusters at step edges to oxide formation. We have shown that the $528.9 \mathrm{eV}$ species is stable in the investigated temperature range, along with the corresponding feature in the valence band located at $2.2 \mathrm{eV}$, in agreement with DFT calculations [35].

\section{Acknowledgments}

This work was supported by the Integrated Mesoscale Architectures for Sustainable Catalysis (IMASC), an Energy Frontier Research Center funded by the US Department of Energy, Office of Science, Basic Energy Sciences under Award No. DE-SC0012573. BE and BAJL were funded by the Chemical and Mechanical Properties of Surfaces, Interfaces and Nanostructures program, in the Division of Materials Sciences and Engineering, of the U.S. Department of Energy (DOE) under Contract DE-AC02-05CH11231. It used resources of the Advance Light Source, a user Facility supported by the Office of Science of the U.S. DOE under Contract DE-AC02-05CH11231. We also thank

Dr. Hendrik Bluhm and Dr. Osman Karslioglu for support during the beamtime at the 11.0.2 endstation of the Advanced Light Source.

\section{References}

[1] R. Schlögl, Angew. Chemie Int. Ed. 54 (2015) 3465-3520.

[2] A. Michaelides, K. Reuter, M. Scheffler, J. Vac. Sci. Technol. A 23 (2005) 1487-1497.

[3] J. Schnadt, J. Knudsen, X.L. Hu, A. Michaelides, R.T. Vang, K. Reuter, Z. Li, E. Lægsgaard, M. Scheffler, F. Besenbacher, Phys. Rev. B 80 (2009) 75424.

[4] C.T. Campbell, J. Catal. 99 (1986) 28-38.

[5] X. Bao, G. Lehmpfuhl, G. Weinberg, R. Schlögl, G. Ertl, J. Chem. Soc. Faraday Trans. 88 (1992) 865.

[6] X. Bao, M. Muhler, T. Schedel-Niedrig, R. Schlögl, Phys. Rev. B 54 (1996) 2249-2262.

[7] V.I. Bukhtiyarov, V. V. Kaichev, I.P. Prosvirin, J. Chem. Phys. 111 (1999) 2169.

[8] X. Bao, M. Muhler, B. Pettinger, R. Schlögl, G. Ertl, Catal. Letters 22 (1993) 215-225.

[9] R.W. Joyner, M.W. Roberts, Chem. Phys. Lett. 60 (1979) 459-462.

[10] R.B. Grant, R.M. Lambert, Surf. Sci. 146 (1984) 256-268.

[11] V.I. Bukhtiyarov, M. Hävecker, V. V Kaichev, A. Knop-Gericke, R.W. Mayer, R. Schlögl, Phys. Rev. B 67 (2003) 235422.

[12] A. Reicho, Ambient Pressure Oxidation of Ag (111) Surfaces: An in-Situ X-Ray Study, Universität Stuttgart, 2008.

[13] T.C.R. Rocha, A. Oestereich, D. V. Demidov, M. Hävecker, S. Zafeiratos, G. Weinberg, V.I. Bukhtiyarov, A. Knop-Gericke, R. 
Schlögl, Phys. Chem. Chem. Phys. 14 (2012) 4554.

[14] S. Böcklein, S. Günther, J. Wintterlin, Angew. Chemie - Int. Ed. 52 (2013) 5518-5521.

[15] S. Günther, S. Böcklein, J. Wintterlin, M. a. Niño, T.O. Menteş, A. Locatelli, ChemCatChem 5 (2013) 3342-3350.

[16] R. Reichelt, S. Gunther, Ro, J. Wintterlin, B. Kubias, B. Jakobi, R. Schlogl, Phys. Chem. Chem. Phys. 9 (2007) 3590-3599.

[17] V.I. Bukhtiyarov, A.I. Nizovskii, H. Bluhm, M. Hävecker, E. Kleimenov, A. Knop-Gericke, R. Schlögl, J. Catal. 238 (2006) $260-269$.

[18] C.T. Campbell, M.T. Paffett, Surf. Sci. 139 (1984) 396-416.

[19] C.T. Campbell, M.T. Paffett, Surf. Sci. 143 (1984) 517-535.

[20] C.I. Carlisle, T. Fujimoto, W.S. Sim, D.A. King, Surf. Sci. 470 (2000) 15-31.

[21] J. Schnadt, A. Michaelides, J. Knudsen, R. Vang, K. Reuter, E. Lægsgaard, M. Scheffler, F. Besenbacher, Phys. Rev. Lett. 96 (2006) 146101.

[22] M. Schmid, A. Reicho, A. Stierle, I. Costina, J. Klikovits, P. Kostelnik, O. Dubay, G. Kresse, J. Gustafson, E. Lundgren, J.N. Andersen, H. Dosch, P. Varga, Phys. Rev. Lett. 96 (2006) 146102.

[23] S.R. Bare, K. Griffiths, W.N. Lennard, H.T. Tang, Surf. Sci. 342 (1995) 185-198.

[24] W.X. Huang, J.M. White, Surf. Sci. 529 (2003) 455-470.

[25] J. Derouin, R.G. Farber, S.L. Heslop, D.R. Killelea, Surf. Sci. 641 (2015) L1-L4.

[26] N.M. Martin, S. Klacar, H. Grönbeck, J. Knudsen, J. Schnadt, S. Blomberg, J. Gustafson, E. Lundgren, J. Phys. Chem. C 118 (2014) $15324-15331$.

[27] M. Salmeron, R. Schlögl, Surf. Sci. Rep. 63 (2008) 169-199.

[28] H. Bluhm, D.F. Ogletree, C. Fadley, Z. Hussain, M. Salmeron, J. Phys. Condens. Matter 14 (2002) L227-L233.

[29] B.J. McIntyre, M. Salmeron, G.A. Somorjai, Rev. Sci. Instrum. 64 (1993) 687-691.

[30] T.E. Jones, T.C.R. Rocha, A. Knop-Gericke, C. Stampfl, R. Schlögl, S. Piccinin, Phys. Chem. Chem. Phys. 17 (2015) $9288-9312$.

[31] T.E. Jones, T.C.R. Rocha, A. Knop-Gericke, C. Stampfl, R. Schlögl, S. Piccinin, ACS Catal. 5 (2015) 5846-5850.

[32] A. Wittstock, V. Zielasek, J. Biener, C.M. Friend, M. Bäumer, Science (80-. ). 327 (2010) 319-322.

[33] S. Tanuma, C.J. Powell, D.R. Penn, Surf. Interface Anal. 21 (1994) 165-176.

[34] W.-X. Li, C. Stampfl, M. Scheffler, Phys. Rev. B 67 (2003) 045408.

[35] W.-X. Li, C. Stampfl, M. Scheffler, Phys. Rev. B 68 (2003) 165412.

[36] A. Michaelides, M.-L. Bocquet, P. Sautet, A. Alavi, D.A. King, Chem. Phys. Lett. 367 (2003) 344-350.

[37] W.-X. Li, C. Stampfl, M. Scheffler, Phys. Rev. B 65 (2002) 16-21.

[38] D. Torres, K.M. Neyman, F. Illas, Chem. Phys. Lett. 429 (2006) 86-90.

[39] M. Todorova, W.X. Li, M. V. Ganduglia-Pirovano, C. Stampfl, K. Reuter, M. Scheffler, Phys. Rev. Lett. 89 (2002) 096103.

[40] J.J. Yeh, I. Lindau, At. Data Nucl. Data Tables 32 (1985) 1-155.

[41] D.Y. Zemlyanov, E. Savinova, a. Scheybal, K. Doblhofer, R. Schlögl, Surf. Sci. 418 (1998) 441-456.

[42] C.-T. Au, S. Singh-Boparai, M.W. Roberts, R.W. Joyner, J. Chem. Soc. Faraday Trans. 79 (1983) 1779-1791.

[43] J. Knudsen, N.M. Martin, E. Grånäs, S. Blomberg, J. Gustafson, J.N. Andersen, E. Lundgren, S. Klacar, A. Hellman, H. Grönbeck, Phys. Rev. B 84 (2011) 115430.

[44] L.H. Tjeng, M.B.J. Meinders, J. van Elp, J. Ghijsena, G.A. Sawatzky, Phys. Rev. B 41 (1990) 3190-3199.

[45] C.T. Campbell, Surf. Sci. 157 (1985) 43-60.

[46] J.N. Andersen, D. Hennig, E. Lundgren, M. Methfessel, R. Nyholm, M. Scheffler, Phys. Rev. B 50 (1994) $17525-17533$.

[47] A. Barrie, N.E. Christensen, Phys. Rev. B 14 (1976) 2442-2447.

[48] J. Leiro, E. Minni, E. Suoninen, J. Phys. F Met. Phys. 13 (1983) 215. 
[49] H. Grönbeck, S. Klacar, N.M. Martin, A. Hellman, E. Lundgren, J.N. Andersen, Phys. Rev. B - Condens. Matter Mater. Phys. 85 (2012) $1-5$.

[50] B.J. Lindberg, K. Hamrin, G. Johansson, U. Gelius, A. Fahlman, C. Nordling, K. Siegbahn, Phys. Scr. 1 (1970) 286.

[51] N. Måtensson, A. Nilsson, J. Electron Spectros. Relat. Phenomena 75 (1995) 209-223.

[52] V.I. Bukhtiyarov, Kinet. Catal. 44 (2003) 420-431.

[53] M. Weinert, R.E. Watson, Phys. Rev. B 51 (1995) 17168-17180.

[54] H. Siegbahn, M. Lundholm, J. Electron Spectros. Relat. Phenomena 28 (1982) 135-138.

[55] H. Siegbahn, J. Phys. Chem. 89 (1985) 897-909.

[56] A.. Boronin, S.. Koscheev, G.. Zhidomirov, J. Electron Spectros. Relat. Phenomena 96 (1998) 43-51.

[57] G.G. Tibbetts, J.M. Burkstrand, Phys. Rev. B 16 (1977) 1536-1541.

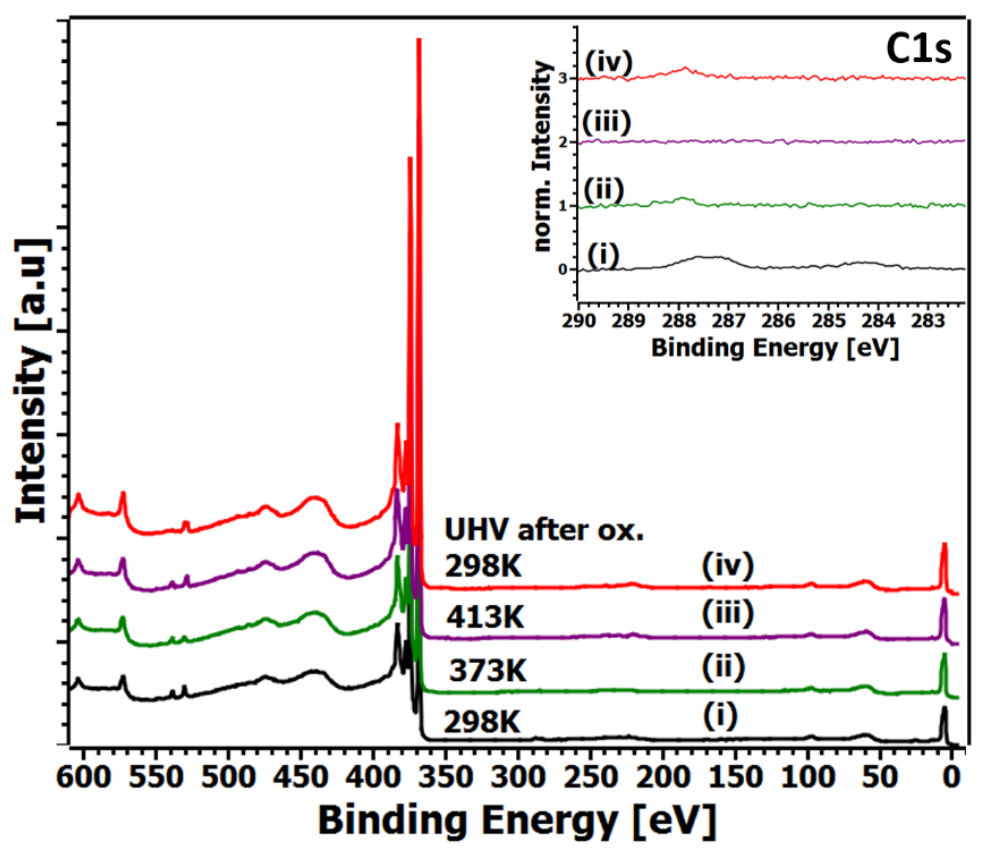

Fig. 1. Survey spectra of the $\operatorname{Ag}(111)$ surface recorded with a photon energy $E_{\mathrm{ph}}=735 \mathrm{eV}$ in the presence of (i) 0.3 Torr $\mathrm{O}_{2}$ at $298 \mathrm{~K}$, (ii) 0.3 Torr $\mathrm{O}_{2}$ at $373 \mathrm{~K}$, (iii) 0.3 Torr $\mathrm{O}_{2}$ at $413 \mathrm{~K}$, and (iv) at $298 \mathrm{~K}$ after pumping back down to UHV ( $5 \times 10^{-9}$ Torr). Inset: C1s spectra normalized to the O1s peaks after background subtraction, respectively (x50 magnification in the survey spectra). No significant peaks other than the Ag and O photoelectron and Auger-Meitner lines are apparent. 

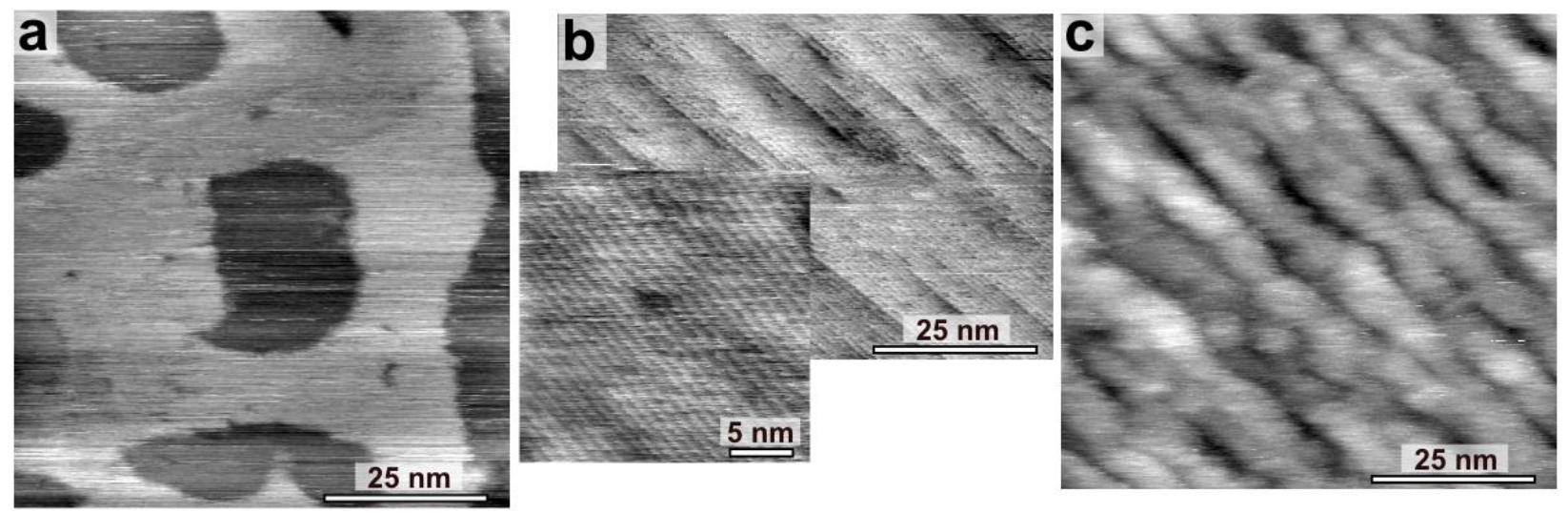

Fig. 2. (a) STM image of the flat part of the $\operatorname{Ag}(111)$ surface in air. The flat terraces remain largely unchanged when changing from UHV to air. (b) STM image in UHV of a defective region of the $\mathrm{Ag}(111)$ surface with a high step density showing narrow terraces with an average width of 4 atoms. Inset: Magnification of (b) to show individual steps. (c) The stepped region changes to one with wider terraces separated by steps several atoms high under ambient conditions. Imaging parameters in UHV: $\left[\mathrm{V}_{\mathrm{b}}=1.0 \mathrm{~V}, \mathrm{I}_{\mathrm{t}}=0.5 \mathrm{nA}\right]$; in air: $\left[\mathrm{V}_{\mathrm{b}}=0.2 \mathrm{~V}, \mathrm{I}_{\mathrm{t}}=0.5 \mathrm{nA}\right]$. 

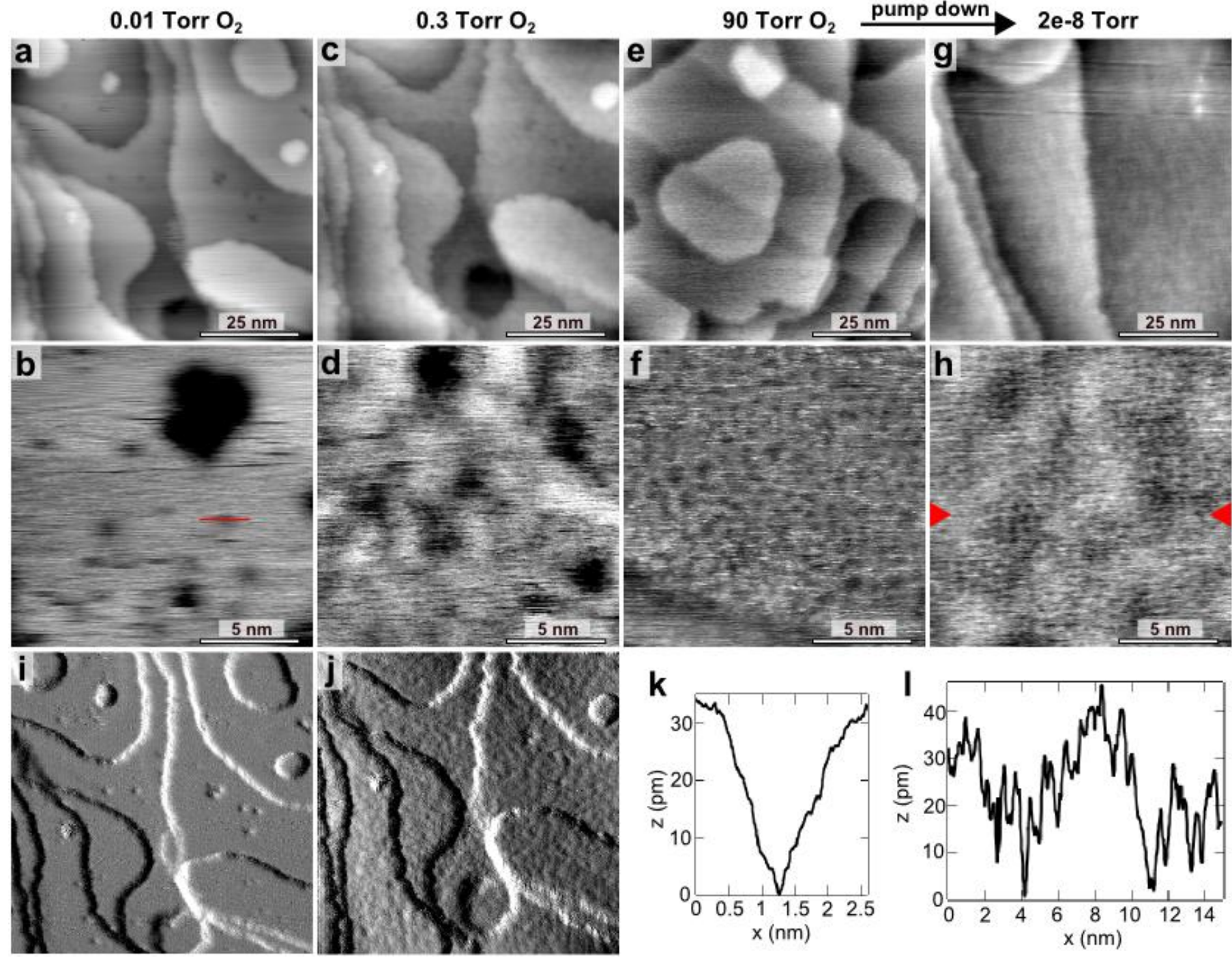

Fig. 3. (Top row) $75 \times 75 \mathrm{~nm}^{2}$ and (central row) $15 \times 15 \mathrm{~nm}^{2} \mathrm{STM}$ images of the $\mathrm{Ag}(111)$ surface as a function of $\mathrm{O}_{2}$ pressure. Overview images (a), (c), (e) and (g) $\left[\mathrm{V}_{\mathrm{b}}=0.5 \mathrm{~V}, \mathrm{I}_{\mathrm{t}}=0.5 \mathrm{nA}\right]$ show that the surface consists of flat terraces separated by monatomic steps. The higher magnification images in the second row were acquired on flat terraces $\left[\mathrm{V}_{\mathrm{b}}=0.1 \mathrm{~V}, \mathrm{I}_{\mathrm{t}}=1.0 \mathrm{nA}\right]$ and show chemisorbed oxygen (either surface or subsurface species), manifest as depressions in tunneling contrast. (i) and (j) are the derivative images of (a) and (c), providing enhanced contrast on the terraces. (k) and (l) are line profiles taken from (b) and (h), respectively, as indicated by the red line and arrows. 

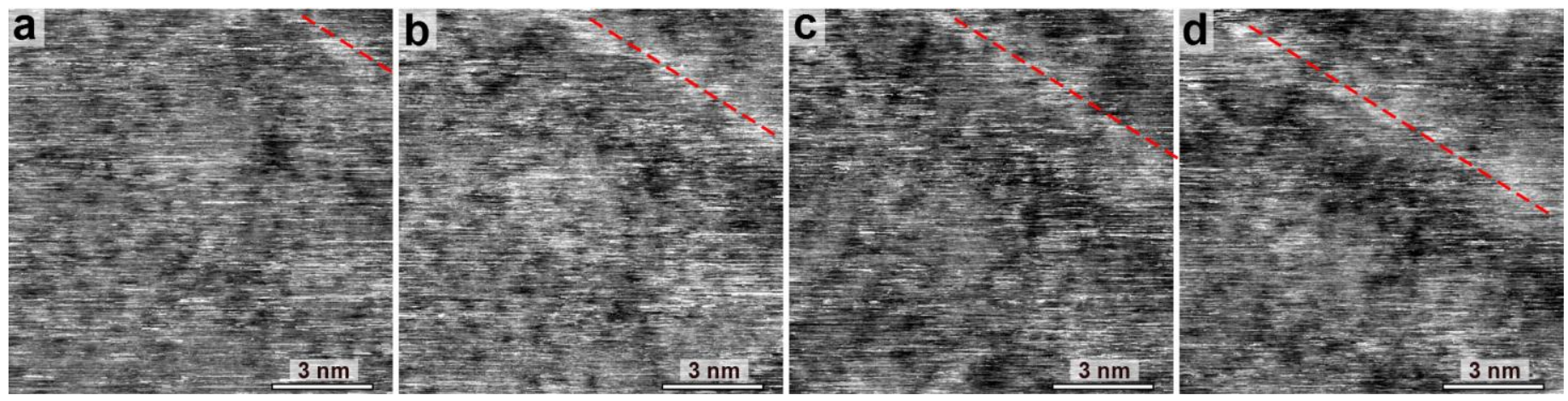

Fig. 4. (a-d) Time-lapsed APSTM images of the $\mathrm{Ag}(111)$ surface in the presence of 10 Torr of $\mathrm{O}_{2}$. The dashed red lines indicate a step edge used as a location marker. Imaging parameters: $\left[\mathrm{V}_{\mathrm{b}}=0.1 \mathrm{~V}, \mathrm{I}_{\mathrm{t}}=1.0 \mathrm{nA}\right]$, time between each image: 96 seconds. The dark spots from the $\mathrm{O}$ atoms are randomly distributed and at different positions in each image due to thermal mobility.
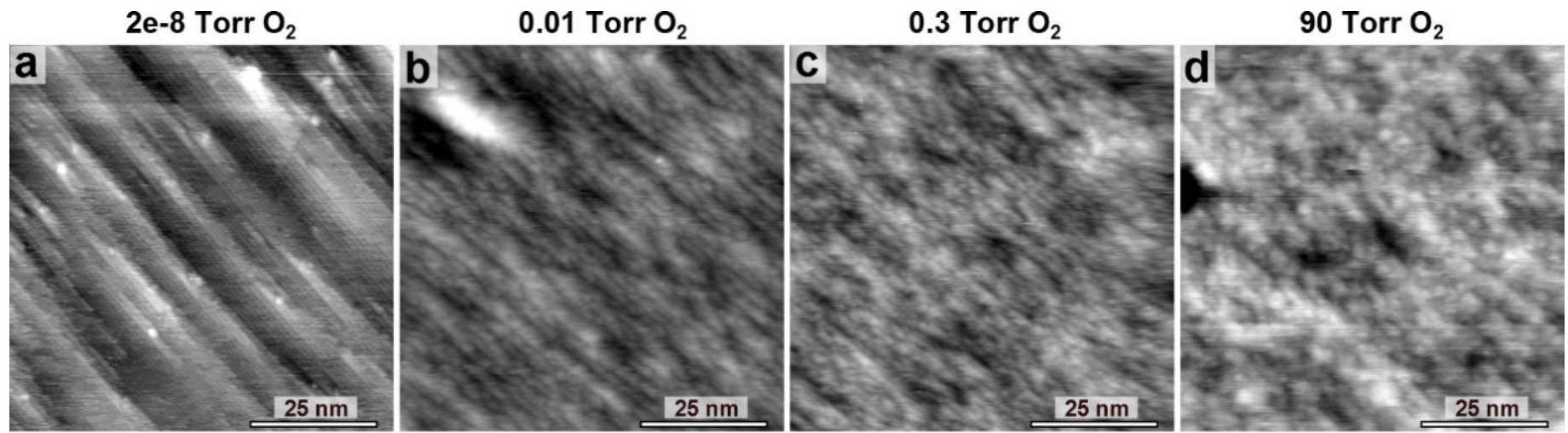

Fig. 5. (a-d) APSTM images showing morphological changes of the stepped Ag regions as a function of $\mathrm{O}_{2}$ pressure. Imaging parameters: $\left[\mathrm{V}_{\mathrm{b}}=1.0 \mathrm{~V}, \mathrm{I}_{\mathrm{t}}=0.5 \mathrm{nA}\right]$. (a) At low pressure the surface appears as in UHV. (b-d) With increasing $\mathrm{O}_{2}$ pressure, the average step width increases and clusters form, indicative of oxide formation. 

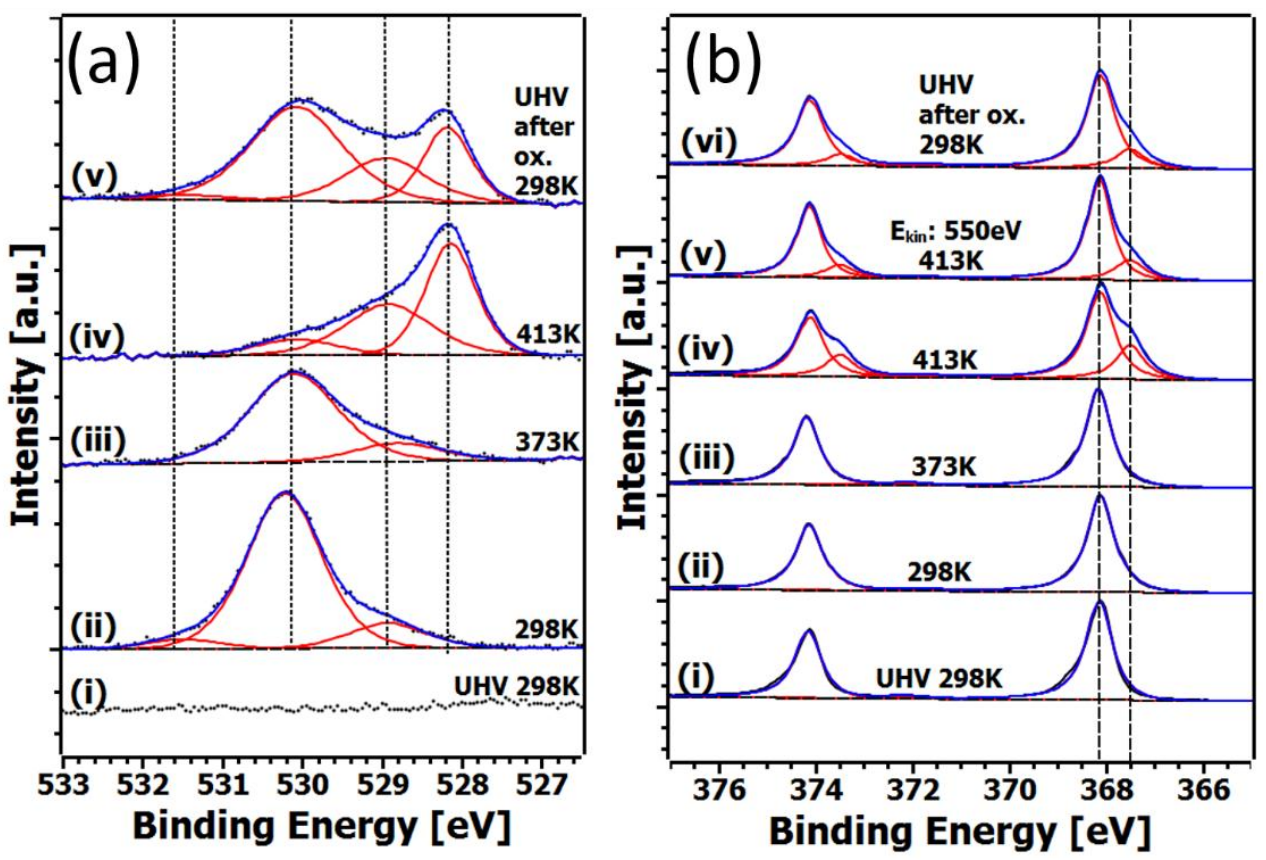

Fig. 6. (a) $\mathrm{O} 1 \mathrm{~s}$ and $\mathrm{Ag} 3 \mathrm{~d}$ spectra acquired at $\mathrm{E}_{\mathrm{kin}}=200 \mathrm{eV}$ (i) in UHV, and (ii-iv) in the presence of 0.3 Torr at 298 $\mathrm{K}, 373 \mathrm{~K}$, and $413 \mathrm{~K}$, respectively. In (a), (v) is taken after cooling down to RT and evacuation of the gas phase. In (b), (v) is acquired at the same condition as (iv) but with $\mathrm{E}_{\text {kin }}$ of $550 \mathrm{eV}$ instead of $200 \mathrm{eV}$. In (b), (vi) is taken after cooling down to RT and evacuation of the gas phase. Black trace: acquired XPS data; red curves: fitting components; blue curves: sum of fitted curves. Vertical dashed lines are guides to the eye. Peak assignments: (a) $531.5 \pm 0.1 \mathrm{eV}$ oxygen in $\mathrm{OH}$-groups, $530.2 \pm 0.1 \mathrm{eV}$ disordered atomic oxygen, $528.9 \pm 0.1 \mathrm{eV}$ oxygen in $\mathrm{Ag}$ oxide (at step edges), and $528.1 \pm 0.1 \mathrm{eV}$ oxygen in the $\mathrm{Ag}(111)-\mathrm{p}(4 \times 4)-\mathrm{O}$ surface reconstruction. (b) $\mathrm{Ag} 3 \mathrm{~d}$ region: The $368.15 \mathrm{eV}$ peak is due to metallic $\mathrm{Ag}$ and the $367.65 \pm 0.1 \mathrm{eV}$ peak due to $\mathrm{Ag}$ atoms in the $\mathrm{Ag}(111)-\mathrm{p}(4 \times 4)-\mathrm{O}$ surface reconstruction [22]. 
Table 1: Atomic intensity ratios of the $\mathrm{O} 1 \mathrm{~s}$ components with respect to the $\mathrm{Ag} 3 \mathrm{~d}_{5 / 2}$ peak. Peak assignments are summarized in the caption to Fig. 6 .

\begin{tabular}{|r|r|r|r|r|}
\hline & $531.5 \mathrm{eV}$ & $530.2 \mathrm{eV}$ & $528.9 \mathrm{eV}$ & $528.1 \mathrm{eV}$ \\
\hline $298 \mathrm{~K}\left(0.3\right.$ Torr $\left.\mathrm{O}_{2}\right)$ & 0.04 & 0.59 & 0.10 & 0.00 \\
\hline $373 \mathrm{~K}\left(0.3\right.$ Torr $\left.\mathrm{O}_{2}\right)$ & 0.00 & 0.30 & 0.06 & 0.00 \\
\hline $413 \mathrm{~K}\left(0.3\right.$ Torr $\left.\mathrm{O}_{2}\right)$ & 0.00 & 0.05 & 0.16 & 0.20 \\
\hline $298 \mathrm{~K}$ (in UHV) & 0.00 & 0.25 & 0.10 & 0.11 \\
\hline
\end{tabular}
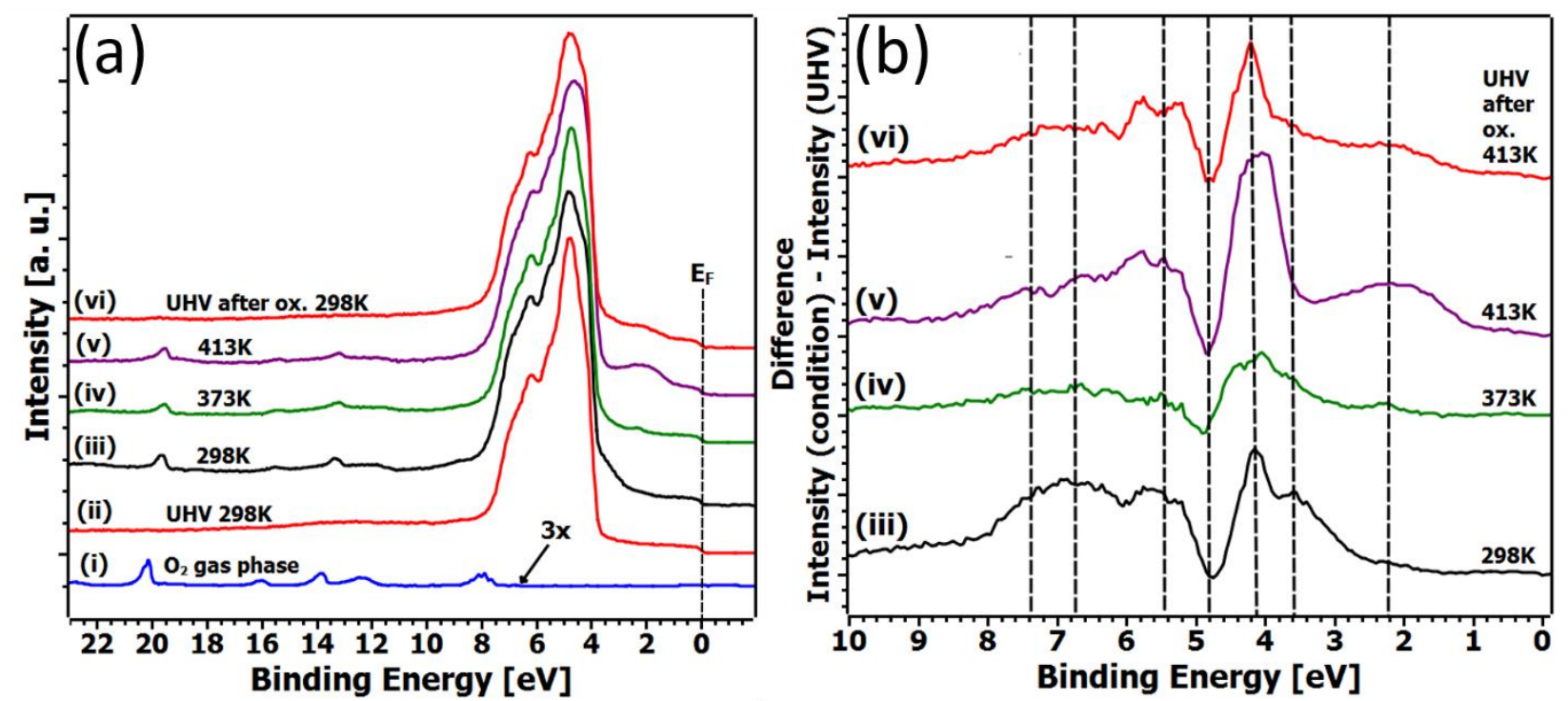

Fig. 7. (a) Valence band spectra of (i) 0.3 Torr of gas phase $\mathrm{O}_{2}$, (ii) $\mathrm{Ag}(111)$ in UHV (iii-v) $\mathrm{Ag}(111$ ) in the presence of 0.3 Torr of $\mathrm{O}_{2}$ at $298 \mathrm{~K}, 373 \mathrm{~K}$, and $413 \mathrm{~K}$, respectively, and (vi) $\mathrm{Ag}(111)$ at $298 \mathrm{~K}$ after the $\mathrm{O}_{2}$ gas was pumped away. (b) Difference spectra of (iii-vi) after subtraction of the UHV reference (ii) shows a clear change in the valence band structure upon exposure to oxygen. 


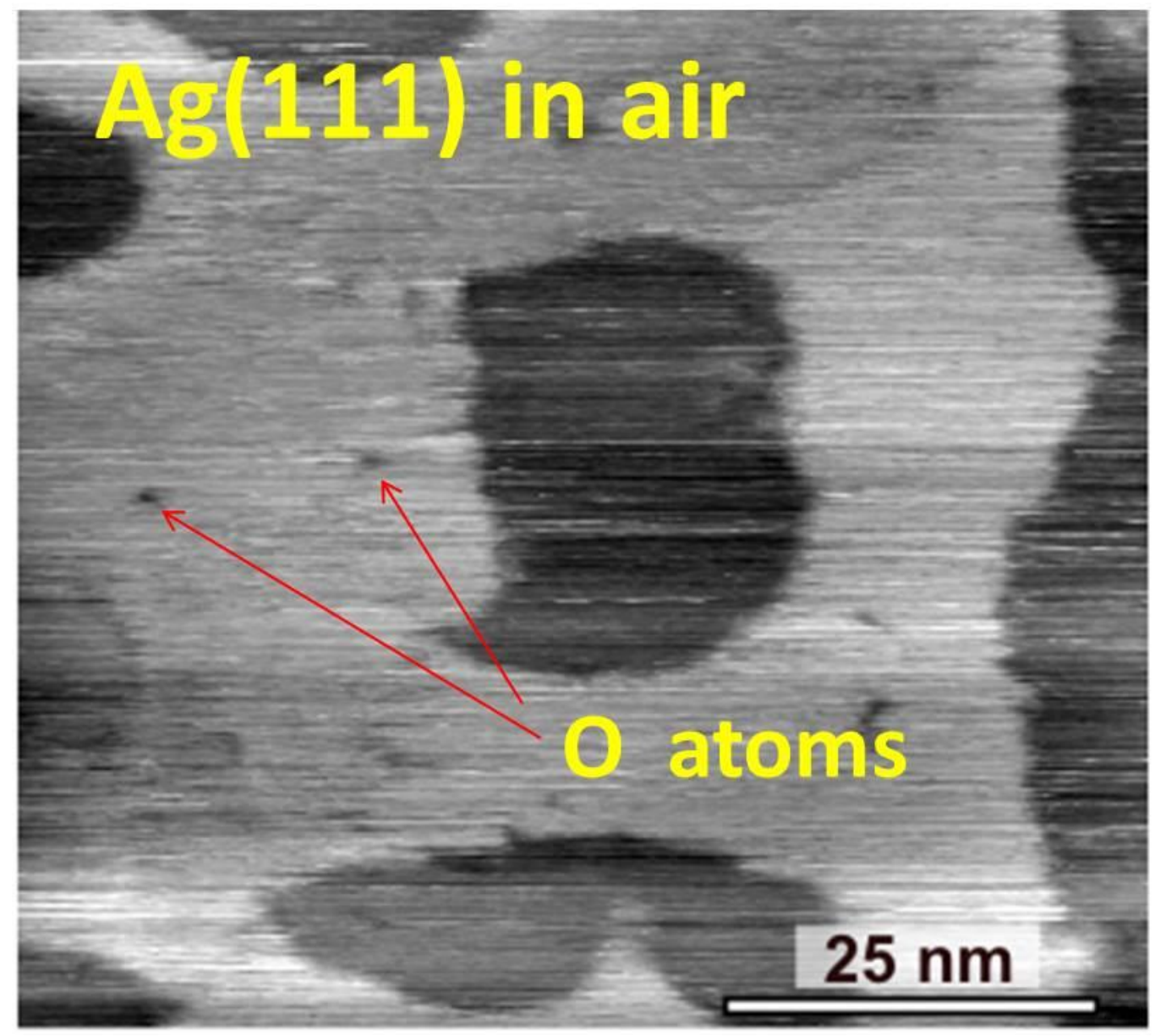

